\title{
Boronic acid-rich dendrimer for efficient intracellular peptide delivery
}

\author{
Jia Lv ${ }^{1}$, Chongyi Liu ${ }^{2}$ Kexin $\mathrm{Lv}^{2}$, Hui Wang ${ }^{1}$ and Yiyun Cheng ${ }^{1,2^{*}}$
}

\begin{abstract}
Interests in intracellular peptide delivery have continued to grow, significantly fueled by the importance of peptides and their mimetics in modern cell biology and pharmaceutical industry. However, efficient intracellular delivery of membrane-impermeable peptides of different polarities remains a challenging task. In this study, we develop a general and robust strategy for intracellular peptide delivery by using a boronic acid-rich dendrimer. The designed material is capable of transporting peptides with different polarities and charge properties into the cytosol of various cell lines without inducing additional cytotoxicity. The transduction efficacy and proteolytic stability of cargo peptides delivered by the boronic acid-rich dendrimer are much superior to peptides conjugated with cell penetrant peptides such as octaarginine. In addition, the bioactivities of pro-apoptotic peptides are maintained after intracellular delivery. This study provides a versatile and robust platform for the intracellular delivery of membrane-impermeable peptides.
\end{abstract}

Keywords: intracellular peptide delivery, dendrimer, boronic acid

\section{INTRODUCTION}

Peptides are short amino acid sequences that could maintain the same or partial biological functions of natural proteins, and have drawn great interests as promising tools in molecular cell biology or drug candidates in clinical trials [1-4]. They were reported to play critical roles in cell adhesive and penetrating, tumor targeting, signal transduction, homeostasis and reproduction, cell apoptosis, nuclear localization, and immunity regulation, i.e., induction of T-cell response against pathogens [516]. Compared with traditional small molecule drugs, peptide-based therapeutics are particularly preferred due to higher specificity towards drug targets, higher safety such as limited adverse effects and immunogenicity, and faster clinical development [17]. As a result, the number of FDA-approved peptide-based drugs is increasing in recent years [5]. The current peptide drugs mainly exert their effect on extracellular membrane targets like ion channels and receptors existing on cell membranes, where they exert their bioactivity through intracellular signaling cascades [1]. Although peptides hold great promise in modern pharmacy, they usually cannot reach intracellular protein targets due to limited membrane-permeability of most peptides [18]. New strategies that are available for the intracellular delivery of membrane-impermeable peptides are highly desired [19].

To facilitate the intracellular delivery, cargo peptides were usually fused with cell penetrant peptides (CPPs), i.e., the transactivator of transcription (TAT) of HIV and octaarginine R8 [20]. The CPP-tagged peptides could translocate cell membranes predominantly via endocytic pathways [21,22]. Alternatively, the cargo peptides were linked to an anthrax lethal factor, which could further bind to protective antigens on cell surface to initiate endocytosis [23]. However, the strategies always require a high dose of peptides to achieve moderate transduction efficiency due to the entrapment of cargoes within endolysosomes in the cells. To address this issue, various peptide delivery carriers such as amphiphilic chemicals, lipid nanoparticles, polymers, nanogels and inorganic nanoparticles were developed [5,17,24-27]. For example, a host-[2] rotaxane containing both cationic arginine and aromatic moieties to host cargo peptides with various polarities was developed, and the complex could enter cells via passive translocation [18]. In a separate study, an endosomolytic anionic polymer was complexed with cationic cargo peptides via electrostatic interactions to form nanoparticles for efficient cytosolic delivery [17]. Alter-

\footnotetext{
${ }^{1}$ South China Advanced Institute for Soft Matter Science and Technology, School of Molecular Science and Engineering, South China University of Technology, Guangzhou 510640, China

${ }^{2}$ Shanghai Key Laboratory of Regulatory Biology, School of Life Sciences, East China Normal University, Shanghai 200241, China

* Corresponding author (email: yycheng@mail.ustc.edu.cn)
} 
natively, peptides to be delivered were incorporated into activatable protein nanoparticles formed through coiledcoil dimerization of polypeptides, and the cargo peptides can be released from the nanoparticles triggered by environment specific enzymes [28]. Very recently, our laboratory developed several cationic polymers such as guanidium-rich polymers and fluoropolymers for efficient intracellular peptide and protein delivery [24,2935]. Despite these advances, the development of an efficient material for cytosolic delivery of peptides with various polarities and charge properties is still a major challenge in this emerging area.

For peptides with short amino acid sequences, there are limited binding sites for the polymeric carriers. In addition, the peptides usually have distinct polarities and charge properties, so it is difficult for peptides to be delivered via ionic interactions just like nucleic acids [3638]. Here, we developed a boronic acid-rich cationic dendrimer for efficient internalization of peptides into different cell lines. Boronic acid is an electron deficient group which could interact with the electron-rich residues on the peptides such as amine and hydroxyl groups via coordination bonding between Lewis acid and base [39-43]. In addition, the cationic dendrimer could bind with anionic groups of cargo peptides via ionic interactions. The combination of these interacting forces facilitates the binding of cargo peptides to the designed material for intracellular peptide delivery. Besides peptide binding, boronic acid-rich materials were reported to successfully circumvent numerous extracellular and intracellular barriers existing in intracellular delivery of biomacromolecules, such as cell targeting, cellular uptake, endosomal escape and cytosolic cargo release [39,44-48]. Based on these rationales, the designed boronic acid-rich dendrimer was expected to have high intracellular translocation efficiency towards peptides with various polarities and isoelectric points (pIs).

\section{EXPERIMENTAL SECTION}

\section{Materials}

Generation 5 polyamidoamine dendrimer (G5 PAMAM) was bought from Dendritech (Midland, USA). Peptides and fluorescein isothiocyanate (FITC)-labelled peptides were synthesized by GL Biochem. (China). 4-(Bromomethyl)phenylboronic acid was obtained from Macklin Biochem. (China). Rhodamine B isothiocyanate (RBITC), genistein, chlorpromazine (CPZ), methyl- $\beta$-cyclodextrin $(\mathrm{M} \beta \mathrm{CD})$ and Hoechst 33342 were bought from SigmaAldrich (USA). Ethylisopropylamiloride (EIPA) was purchased from MedChem Express (USA). Lactate dehydrogenase (LDH) assay kit, annexin V-FITC apoptosis kit, Lysotracker Red were provided by Beyotime (China). Trypsin was purchased from Macklin (China).

\section{Synthesis of BDP and RBITC-labeled BDP}

4-(Bromomethyl)phenylboronic acid $(128 \mu \mathrm{mol})$ was reacted with dendrimer at a molar ratio of $128: 1$ in dimethyl sulfoxide at $70^{\circ} \mathrm{C}$ for $24 \mathrm{~h}$ followed by dialysis and freeze-drying. The purified material was characterized by ${ }^{1} \mathrm{H}$ NMR spectroscopy (Bruker, $500 \mathrm{MHz}$ ). For synthesis of RBITC-labeled boronic acid-decorated dendrimer (BDP), $0.25 \mu \mathrm{mol}$ BDP was reacted with $0.75 \mu \mathrm{mol}$ RBITC in deionized water for $24 \mathrm{~h}$ followed by dialysis and freeze-drying to obtain BDP-RBITC.

\section{Preparation and characterization of $\mathrm{BDP} /$ peptide complexes}

BDP was added into peptide solutions at various mass ratios. The complex solutions were incubated for $30 \mathrm{~min}$. The formed particles were characterized by dynamic light scattering (Malvern, UK) and transmission electron microscope (HITACHI, Japan), respectively. Polymer/peptide binding and in vitro peptide release were tested by fluorescence resonance energy transfer (FRET). BDPRBITC was mixed with peptide-FITC (1.5:1, mass ratio) and incubated for $30 \mathrm{~min}$. The fluorescence spectrum of the sample was tested by fluorescence spectrophotometer (F4500, HITACHI, Japan). Peptide binding ratios of BDP were tested as follows: the $\mathrm{BDP} /$ peptide complexes were incubated for $30 \mathrm{~min}$, and then diluted with distilled water or cell culture buffer (cell culture medium without phenol red). The solutions were centrifuged at $12,000 \mathrm{rmin}^{-1}$ for $20 \mathrm{~min}$, and the concentrations of peptides in the supernatant were measured. The corresponding peptides without addition of polymer were tested as controls. The peptide binding ratio (\%) of BDP to each peptide was calculated as follows: $\left(C_{\text {control }^{-}}\right.$ $\left.C_{\mathrm{BDP} / \text { peptide complexes }}\right) / C_{\text {control }} \times 100$, where $C$ represents the concentrations of peptides in the corresponding supernatant. For in vitro peptide release, the BDP-RBITC/ peptide-FITC complexes were added with a competitor protein bovine serum albumin $\left(0.5 \mathrm{mg} \mathrm{mL}^{-1}\right)$ and then the fluorescence spectrum of the yielding mixture solution was measured.

\section{Cell culture and cytosolic peptide delivery}

The cells were cultured in media (Dulbecco's modified Eagle medium (DMEM) for human cervical cancer cells 
(HeLa), human embryonic kidney cells (HEK293), human breast cancer cells (MCF-7), mouse brown adipose tissue cells (BAT) and inguinal white adipocytes cells (iWAT), and minimum essential medium (MEM) for human breast cancer cells (MDA-MB-231), GIBCO) containing $10 \%$ fetal bovine serum (FBS, Gemini, USA). For intracellular peptide delivery experiments, the cells ( 25,000 each well) were cultured in 48-well plate overnight till 90\% confluence. Cargo peptides were complexed with BDP at various mass ratios. The complex solution was diluted with $50 \mu \mathrm{L} N$-2-hydroxyethylpipera-zine- $N$ 2-ethanesulfonic acid (HEPES) buffer and further incubated for $30 \mathrm{~min}$ before the addition of $250 \mu \mathrm{L}$ serumfree medium. The cells were then incubated with the complex for different periods, and the internalized peptides by cells were analyzed via confocal microscopy (LeicaSP8, Germany) and flow cytometry (BD LSRFortessa, USA). The cytotoxicity of BDP $\left(0-30 \mu \mathrm{g} \mathrm{mL}^{-1}\right)$ on the treated cells as described in the intracellular peptide delivery experiments was measured by 3-(4,5-dimethyl-2thiazolyl)-2,5-diphenyl-2- $H$-tetrazolium bromide (MTT) assay.

\section{LDH release and apoptosis assay}

The HeLa cells were seeded in 96-well plate ( $\sim 5000$ each well) overnight till $50 \%$ confluence, and then treated with the DBP/peptide complexes or control peptides for $4 \mathrm{~h}$ in the absence of serum. Then, the medium was removed and replenished with $250 \mu \mathrm{L}$ medium (10\% FBS) and cultured for $20 \mathrm{~h}$. LDH release from the treated cells was tested according to the manufacturer's protocol (Beyotime, China). For the apoptosis assay, cells were cultured with the formulations as described above, then stained by the FITC-Annexin V apoptosis kit (Beyotime, China) and analyzed by flow cytometry. For cell membrane leakage assay, HeLa cells were cultured with the complexes as described above. After being washed with phosphate buffer saline (PBS) thrice, the treated cells were cultured with $10 \mu \mathrm{mol} \mathrm{L}^{-1}$ calcein for $10 \mathrm{~min}$, and then washed with PBS thrice before observation by confocal microscopy.

\section{Internalization mechanism}

The HeLa cells were pretreated with inhibitors such as EIPA $\quad\left(30 \mu \mathrm{g} \mathrm{mL}^{-1}\right), \quad$ genistein $\left(189 \mu \mathrm{g} \mathrm{mL}^{-1}\right), \quad \mathrm{CPZ}$ $\left(7 \mu \mathrm{gL}^{-1}\right)$ and $\mathrm{M} \beta \mathrm{CD}\left(13 \mathrm{mg} \mathrm{mL}^{-1}\right)$ for $1 \mathrm{~h}$ before the addition of complexes. Fluorescence of treated cells was analyzed by flow cytometry and confocal microscopy. Cells treated with $\mathrm{BDP} /$ peptide complex at $37^{\circ} \mathrm{C}$ without any inhibitor were tested as control $(100 \%$ fluorescence intensity). The intracellular peptide delivery experiment was also conducted at $4^{\circ} \mathrm{C}$ to reveal the role of energy during internalization. To monitor intracellular localization of the cargo peptides, cells were treated with BDP/ peptide complex for 2 and $4 \mathrm{~h}$, respectively. The acidic compartments and nuclei of the treated cells were stained by Lysotracker red $\left(200 \mathrm{nmol} \mathrm{L}^{-1}\right)$ and Hoechst 33342 $\left(2.5 \mu \mathrm{g} \mathrm{mL}^{-1}\right)$ at $37^{\circ} \mathrm{C}$ for 20 and $10 \mathrm{~min}$, respectively. Then the treated cells were washed with PBS thrice before being observed by confocal microscopy.

\section{Proteolytic stability}

BDP $(6 \mu \mathrm{g})$ was mixed with peptides at a weight ratio of 1.5:1, added with $50 \mu \mathrm{L}$ HEPES buffer and further incubated for $0.5 \mathrm{~h}$. The complex was treated with $0.2 \mu \mathrm{g}$ trypsin for $2 \mathrm{~h}$. After that, the complex solution was diluted with $250 \mu \mathrm{L}$ medium without FBS and incubated with the cells. After incubation for $4 \mathrm{~h}$, the medium was removed and the treated cells were washed with PBS thrice. The internalized peptides were measured by flow cytometry. R8- or TAT-conjugated peptides were tested as described above.

\section{Data analysis}

The data were presented as mean \pm SD ( $n=3$ for the peptide delivery experiments, and $n=5$ for MTT assay). Statistically significant difference was analyzed by student's $t$-test. ${ }^{\text {n.s. }} p \geq 0.05,{ }^{*} p<0.05,{ }^{* *} p<0.01$ and ${ }^{* * *} p<0.001$.

\section{RESULTS AND DISCUSSION}

The dendrimer was conjugated with 4-(bromomethyl) phenylboronic acid by a facile chemistry. According to the ${ }^{1} \mathrm{H}$ NMR result (Fig. S1), a BDP with 68 phenylboronic acid modified on each dendrimer was obtained (Fig. 1a). Peptides with various polarities and pIs were labeled with FITC at the N-terminal during synthesis to monitor the intracellular peptide delivery (Fig. 1b). BDP was complexed with the cargo peptides in Fig. 1b by gently mixing the two species together at a weight ratio of 1.5:1 (polymer to peptide). All the peptides alone showed poor translocation efficiency on HeLa cells; however, the presence of BDP significantly improved the translocation efficiencies of the investigated peptides as confirmed by flow cytometry analysis (Fig. 1c) and confocal images (Fig. 1d). The addition of trypan blue, a membrane-impermeable fluorescence quencher, only slightly decreased the fluorescence on the treated cells (Fig. S2), which suggested the internalization of cargo peptides by the treated cells. The peptides P2, P4 and P5 with distinct charge properties and hydrophobicities were selected as 
a

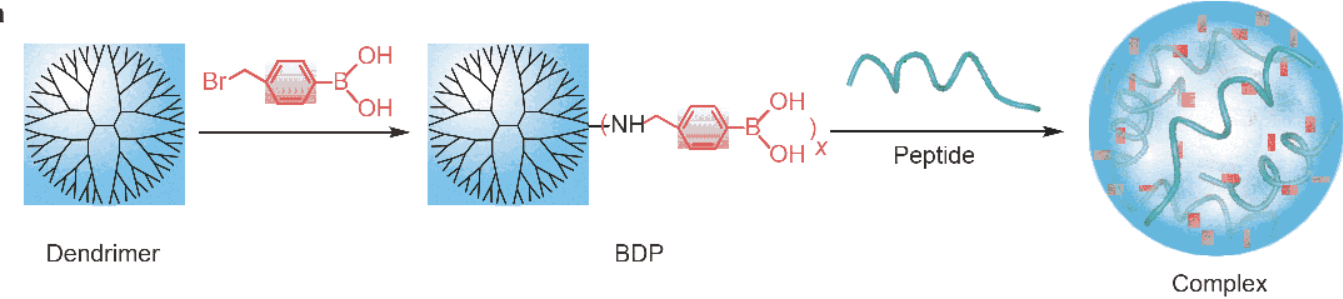

b

\begin{tabular}{ccccc}
\hline Peptides & Sequence & Charge & $\mathrm{Kd}$ & $\mathrm{pl}$ \\
\hline P1 & VPVEAVDGG & -3 & 5 & 0.6 \\
P2 & EERHGGFLC & -2 & -6.4 & 4.2 \\
P3 & GLARDTIYF & -1 & 2.5 & 3.1 \\
P4 & FKSTWYMHH & 0 & -9.3 & 7.9 \\
P5 & VIVPRYLKC & 1 & 7.9 & 9.2 \\
P6 & DKKKKHHSM & 2 & -24.4 & 10.5 \\
\hline
\end{tabular}

c

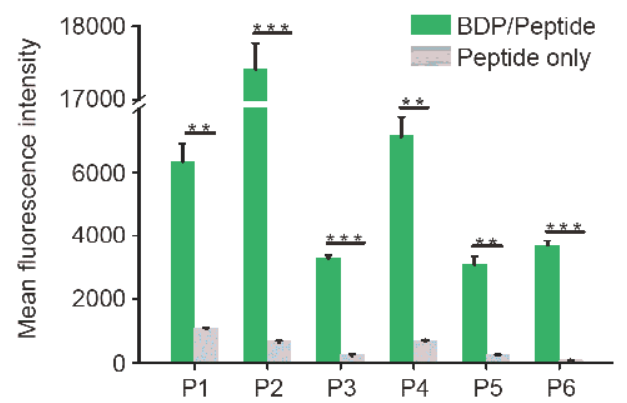

d

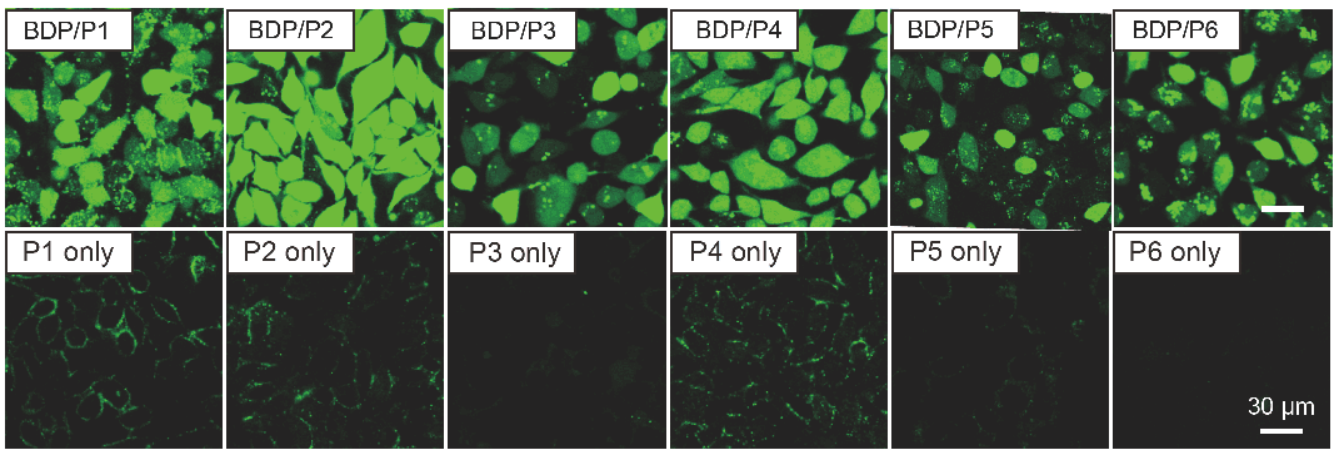

Figure 1 Synthesis of BDP and its efficacies in cytosolic delivery of peptides with various properties. (a) Synthesis of BDP and the preparation of BDP/peptide complexes. (b) Properties of cargo peptides P1-P6, the hydrophobicity was calculated according to Kyte-Doolittle hydrophobicity value (Kd) [48]. Intracellular peptide delivery into HeLa cells by BDP for $4 \mathrm{~h}$ was measured by flow cytometry (c) and confocal microscopy (d). Peptides without addition of BDP (peptide only) were used as negative controls. The concentrations of peptides and BDP were 13.3 and $20 \mu \mathrm{g} \mathrm{mL}^{-1}$, respectively.

model peptides in further studies.

As shown in Fig. 2a, the peptide delivery efficacies of BDP are comparable or much superior to those of CPPtagged peptides such as TAT- and R8-conjugated peptides. The binding of cargo peptides with BDP was confirmed by FRET (Fig. S3), dynamic light scattering and transmission electron microscopy analyses (Fig. S4). The binding ratios of BDP to the peptides were around or above $60 \%$ in distilled water, and diluting with cell culture buffer only slightly reduced the peptide binding ratios of BDP (Fig. S5). The successful binding of cargo peptides with BDP not only facilitates their membrane transporting but also protects them from enzymatic degradation. To confirm this hypothesis, TAT- and R8-conjugated peptides and $\mathrm{BDP} /$ peptide complexes were pre-incubated with trypsin for $2 \mathrm{~h}$, and then used to treat HeLa cells for $4 \mathrm{~h}$ before being measured by flow cytometry. The fluorescence intensities of cells treated with R8- and TAT-conjugated peptides were significantly decreased in the presence of trypsin, while those with $\mathrm{BDP} /$ peptide complexes were slightly changed under the same condition (Fig. 2b, c and Fig. S6). These results clearly demonstrated the excellent proteolytic stability of BDP/ peptide complexes, which is critical for maintaining the bioactivity of peptides during intracellular delivery. Moreover, the carrier BDP shows minimal cytotoxicity at various concentrations (Fig. S7). Further studies suggested that the internalization of $\mathrm{BDP} / \mathrm{P} 2$ complexes by 

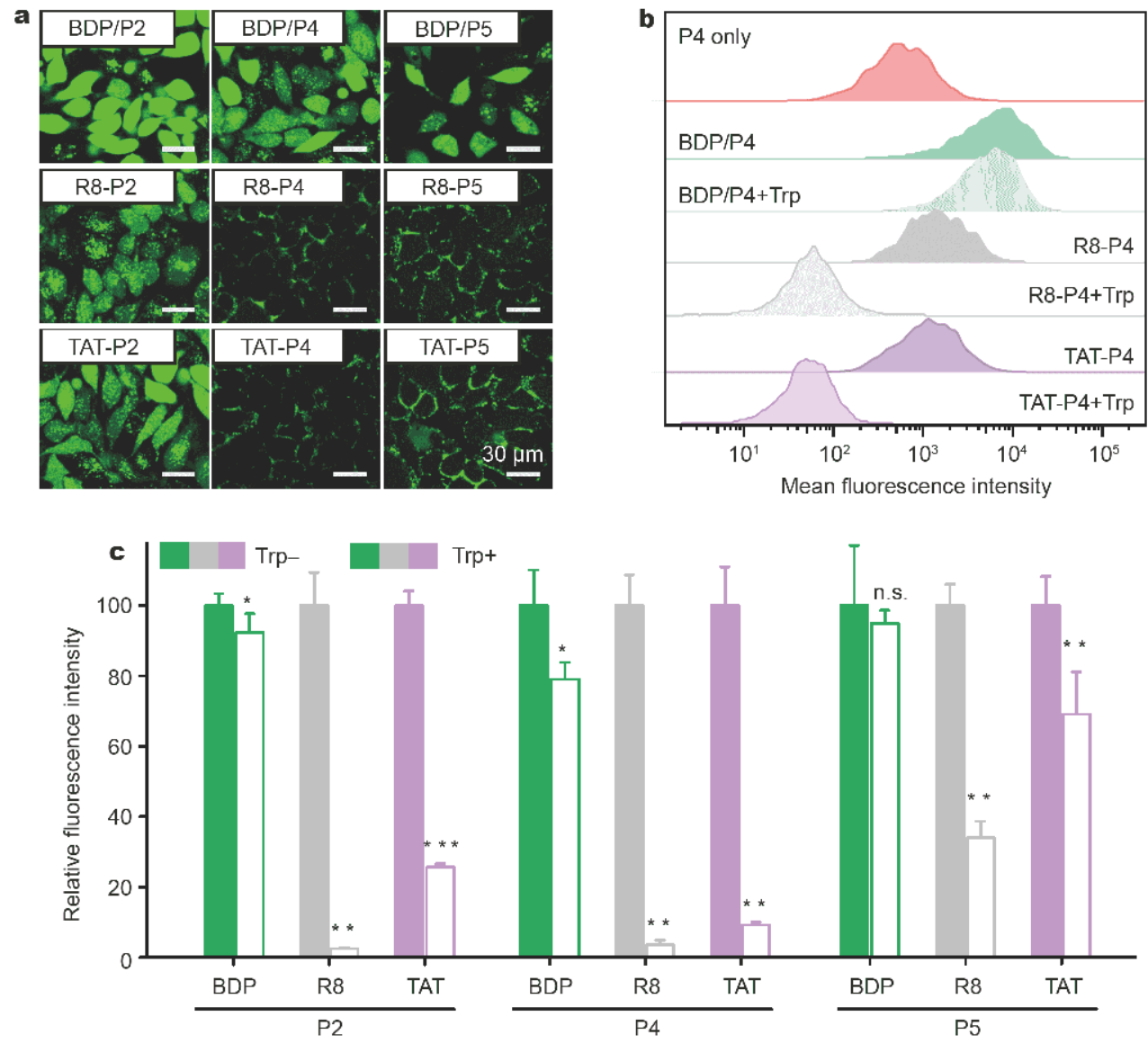

Figure 2 The comparison of BDP with CPP. (a) Confocal images of HeLa cells incubated with BDP/peptide, TAT- and R8-conjugated peptides for $4 \mathrm{~h}$. (b) Flow cytometry of cells incubated by BDP/P4, R8-P4, TAT-P4, respectively, for $4 \mathrm{~h}$. The samples were pre-treated without or with $4 \mu \mathrm{g} \mathrm{mL}^{-1}$ trypsin (Trp) for $2 \mathrm{~h}$ before incubation with cells. (c) Relative fluorescence intensities of HeLa cells treated with BDP/peptide, R8-peptide, or TATpeptide, respectively, for $4 \mathrm{~h}$. The samples were pre-treated without or with $4 \mu \mathrm{g} \mathrm{mL} \mathrm{m}^{-1}$ trypsin for $2 \mathrm{~h}$ before incubation with cells. For the samples without trypsin treatment, the relative fluorescence intensity was set as 100\%. The concentrations of peptides (P2, P4 and P5) and BDP were 13.3 and $20 \mu \mathrm{g} \mathrm{mL}^{-1}$, respectively. The molar concentrations of R8- and TAT-conjugated peptides were equal to those of P2, P4 and P5 in the BDP complexes, respectively.

HeLa cells was energy-dependent and involved with multiple pathways including macropinocytosis-, caveolindependent endocytosis and clathrin-dependent endocytosis (Fig. 3a, b). Boronic acid-rich polymers were reported to circumvent multiple intracellular barriers existing during gene and protein delivery [39,44,49-52]. The internalized BDP/peptide complexes showed efficient endosomal escape after $4 \mathrm{~h}$ incubation with the cells (Fig. S8). The bound peptides could be released from BDP in the presence of abundant proteins in the cytoplasm (Fig. S9). We further investigated the effects of peptide dosage and incubation time on the intracellular delivery efficacy. As shown in Fig. S10, fluorescence intensity of the BDP/ P2 complex-treated cells increased in proportion to peptide dosage, and the internalization was saturated at
$8 \mu \mathrm{g}$ peptide. In addition, the intracellular peptide delivery by BDP also depended on the incubation time. The fluorescence intensity of cells increased with incubation time, and was saturated when the incubation time reached $8 \mathrm{~h}$. Besides HeLa cells, BDP was effective when delivering P2 into various cells such as HEK293, MDAMB-231, MCF-7, BAT, and iWAT (Fig. 3c).

We further investigated whether the bioactivity of cargo peptides could be maintained after intracellular delivery by BDP. A membrane-impermeable peptide ACSAG (AG5) with potential pro-apoptotic activity was used as the model peptide to test the feasibility of BDP in the delivery of bioactive peptides [53,54]. As shown in Fig. 4a, b, AG5-FITC showed minimal cellular uptake; however, the BDP/AG5-FITC complex exhibited dramatically in- 

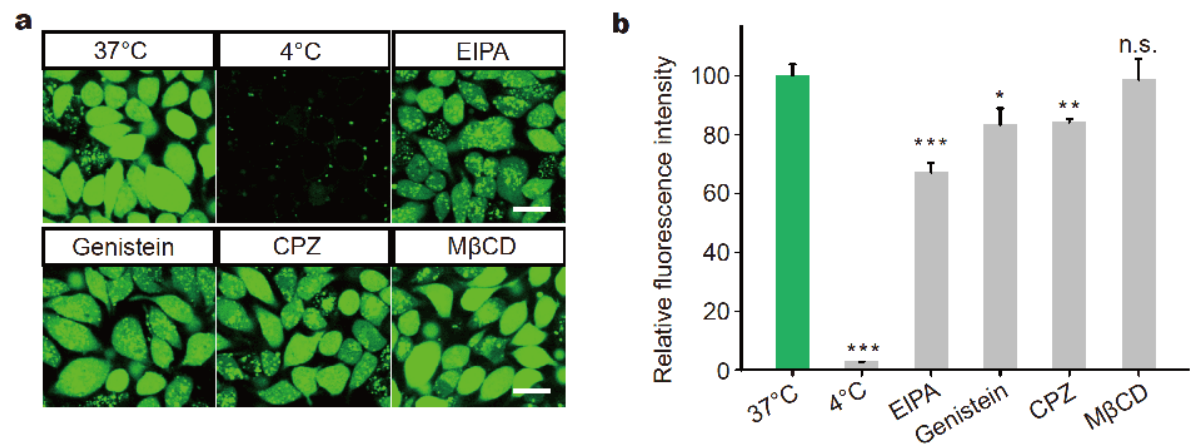

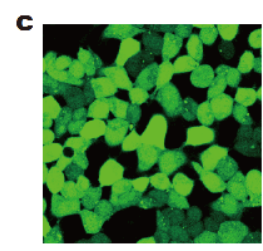

HEK293

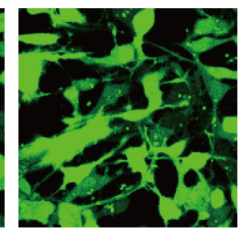

MDA-MB-231

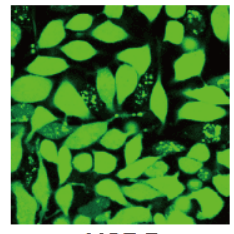

MCF-7

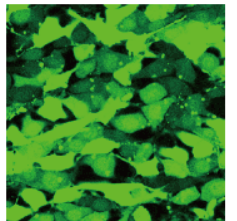

BAT

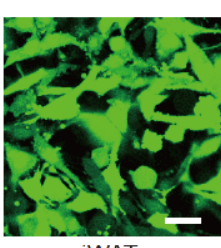

iWAT

Figure 3 Internalization pathways of BDP/P2 complex by HeLa cells and peptide delivery efficacy of BDP on other cell lines. Cells were pre-incubated with inhibitors including EIPA (inhibitor of macropinocytosis), genistein (inhibitor of caveolin-involved pathway), CPZ (inhibitor of clathrininvolved pathway) and $\mathrm{M} \beta \mathrm{CD}$ (inhibitor of lipid raft) for $1 \mathrm{~h}$ before intracellular peptide delivery. The cells treated with BDP/P2 complex for $4 \mathrm{~h}$ were observed by confocal microscope (a) or quantitatively measured with flow cytometry (b). (c) Confocal images of HEK 293, MDA-MB-231, MCF-7, BAT, and iWAT treated with BDP/P2 complexes for $4 \mathrm{~h}$. The concentrations of P2 and BDP were 13.3 and $20 \mu \mathrm{g} \mathrm{mL} \mathrm{L}^{-1}$, respectively. The scale bar is $30 \mu \mathrm{m}$.

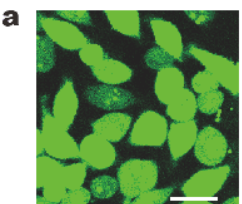

BDP/AG5-FITC

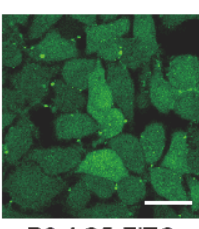

R8-AG5-FITC

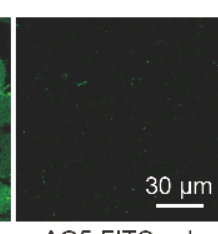

AG5-FITC only

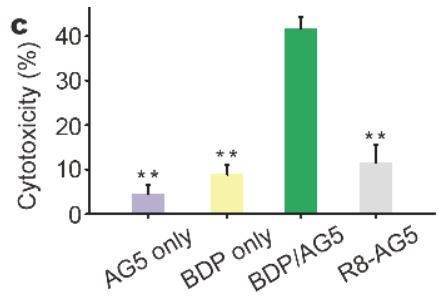

b

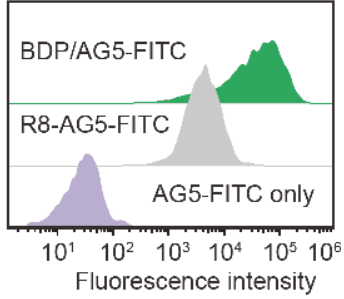

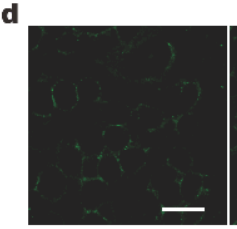

AG5 only

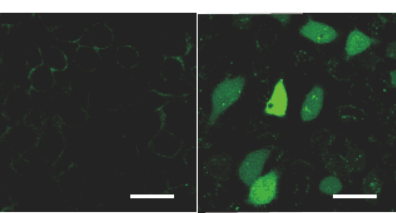

BDP only

BDP/AG5

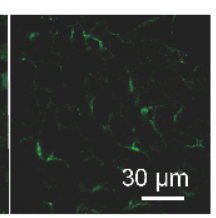

R8-AG5
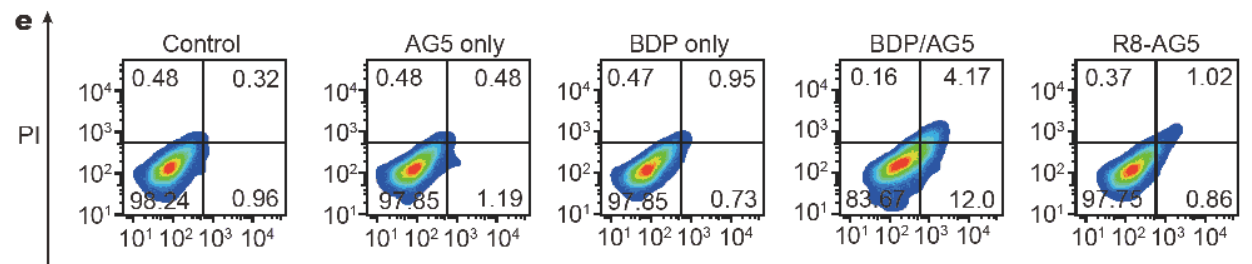

Annexin V-FITC

Figure 4 Intracellular delivery of AG5 by BDP. Fluorescence images (a) and intensity (b) of HeLa cells treated with BDP/AG5-FITC, R8-AG5-FITC, and AG5-FITC, respectively, for $4 \mathrm{~h}$. (c) LDH release from cells treated with AG5, BDP, BDP/AG5 complex and R8-AG5 for 24 h. (d) Confocal images of cells with calcein treatment after incubation with AG5, BDP, BDP/AG5 complex and R8-AG5 for $24 \mathrm{~h}$, respectively. (e) Apoptosis of cells treated with AG5, BDP, BDP/AG5 complex, and R8-AG5 for $24 \mathrm{~h}$. The concentrations of BDP, AG5-FITC and AG5 were $20,13.3$, and $83.3 \mu \mathrm{g} \mathrm{mL}{ }^{-1}$, respectively. The molar concentration of R8-AG5 was equal to that of AG5 used in BDP/AG5 complex. 

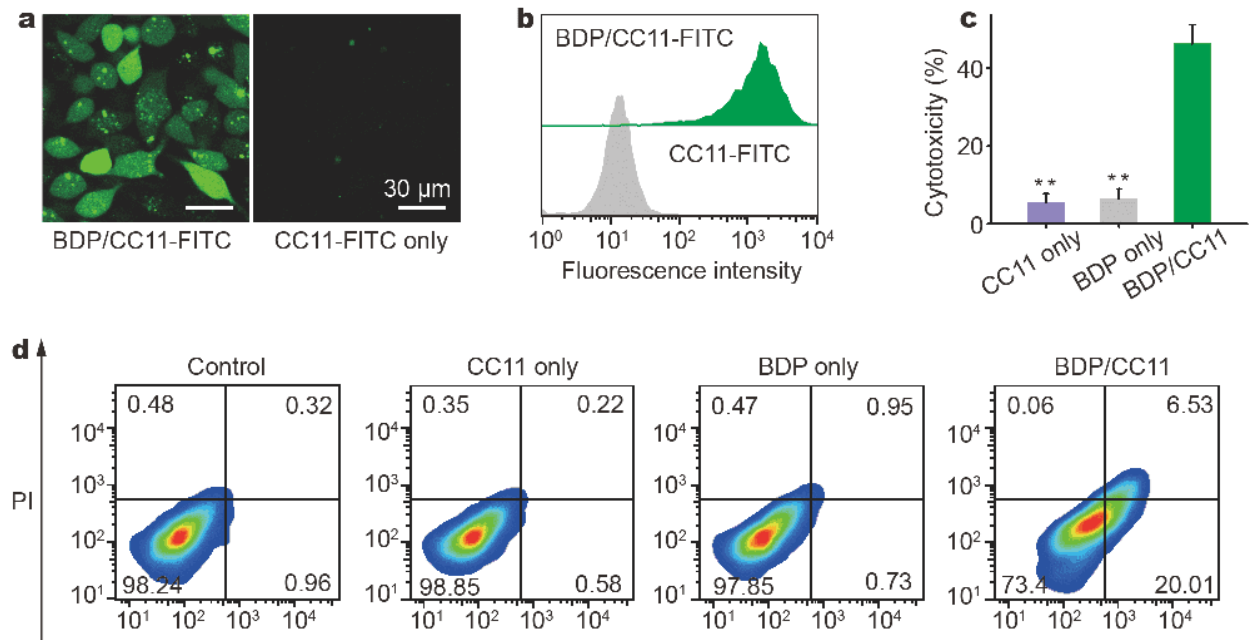

Annexin V-FITC

Figure 5 Intracellular delivery of CC11 by BDP. Fluorescence images (a) and mean fluorescence intensity (b) of cells incubated with BDP/CC11 complex and CC11, respectively, for $4 \mathrm{~h}$. The peptide was labeled with FITC to monitor its intracellular delivery. (c) LDH release from HeLa cells treated with BDP/CC11, BDP, and CC11 for $24 \mathrm{~h}$. (d) Apoptosis of HeLa cells incubated with CC11, BDP, and BDP/CC11 complex for $24 \mathrm{~h}$. The concentrations of BDP, CC11-FITC, and CC11 were $20,13.3$, and $50 \mu \mathrm{g} \mathrm{mL}^{-1}$, respectively.

creased cellular internalization, which was much higher than that of R8-conjugated AG5-FITC. We further tested the anti-cancer activities of AG5, R8-AG5 and BDP/AG5 on HeLa cells. As shown in Fig. 4c-e, BDP/AG5 complex caused much increased membrane leakage, cell apoptosis and death on HeLa cells in comparison with AG5 and R8AG5, and the toxicity of complex was not caused by the carrier BDP. The peptide CWMSPRHLGTC (CC11) is a cyclic pro-apoptotic peptide that can block the protein kinase CK2 phosphorylation and induce apoptosis in cancer cells [55]. As shown in Fig. 5a, b, FITC-labeled CC11 itself showed poor membrane permeability into HeLa cells, while BDP could efficiently translocate the peptide into cytosol of the treated cells. More importantly, the cancer cells treated with BDP/CC11 complex showed significant apoptosis, while CC11 and BDP only induced minimal apoptosis in the treated cells (Fig. 5c, d). These results suggest that BDP-mediated intracellular peptide delivery can preserve the bioactivity of cargo peptides.

\section{CONCLUSIONS}

In summary, the designed material BDP permits the efficient translocation of cargo peptides with various properties across plasma membranes to exert their functions inside the cells. The delivered cargo peptides maintain their bioactivities after intracellular release. In addition, the designed material shows low toxicity on treated cells. The current study provides an efficient and robust strategy to design vectors for intracellular peptide delivery.

Received 25 September 2019; accepted 24 October 2019; published online 20 November 2019

1 Acar H, Ting JM, Srivastava S, et al. Molecular engineering solutions for therapeutic peptide delivery. Chem Soc Rev, 2017, 46: 6553-6569

2 Zhang C, Liu LH, Qiu WX, et al. A transformable chimeric peptide for cell encapsulation to overcome multidrug resistance. Small, 2018, 14: 1703321

3 Cheng H, Zheng RR, Fan GL, et al. Mitochondria and plasma membrane dual-targeted chimeric peptide for single-agent synergistic photodynamic therapy. Biomaterials, 2019, 188: 1-11

4 Wang C, Sang H, Wang Y, et al. Foe to friend: supramolecular nanomedicines consisting of natural polyphenols and bortezomib. Nano Lett, 2018, 18: 7045-7051

5 Suma T, Cui J, Müllner M, et al. Modulated fragmentation of proapoptotic peptide nanoparticles regulates cytotoxicity. J Am Chem Soc, 2017, 139: 4009-4018

6 Field LD, Delehanty JB, Chen YC, et al. Peptides for specifically targeting nanoparticles to cellular organelles: quo vadis? Acc Chem Res, 2015, 48: 1380-1390

7 Eom KD, Miao Z, Yang JL, et al. Tandem ligation of multipartite peptides with cell-permeable activity. J Am Chem Soc, 2003, 125: $73-82$

8 Zhen Z, Tang W, Wang M, et al. Protein nanocage mediated fibroblast-activation protein targeted photoimmunotherapy to enhance cytotoxic $\mathrm{T}$ cell infiltration and tumor control. Nano Lett, 2017, 17: 862-869

9 Li S, Zou R, Tu Y, et al. Cholesterol-directed nanoparticle as- 
semblies based on single amino acid peptide mutations activate cellular uptake and decrease tumor volume. Chem Sci, 2017, 8: 7552-7559

10 Jiang Y, Zhang J, Meng F, et al. Apolipoprotein E peptide-directed chimeric polymersomes mediate an ultrahigh-efficiency targeted protein therapy for glioblastoma. ACS Nano, 2018, 12: 1107011079

11 Sun H, Dong Y, Feijen J, et al. Peptide-decorated polymeric nanomedicines for precision cancer therapy. J Control Release, 2018, 290: $11-27$

12 Xiong $\mathrm{M}$, Han Z, Song Z, et al. Bacteria-assisted activation of antimicrobial polypeptides by a random-coil to helix transition. Angew Chem Int Ed, 2017, 56: 10826-10829

13 Song Z, Han Z, Lv S, et al. Synthetic polypeptides: from polymer design to supramolecular assembly and biomedical application. Chem Soc Rev, 2017, 46: 6570-6599

14 Tang H, Yin L, Kim KH, et al. Helical poly(arginine) mimics with superior cell-penetrating and molecular transporting properties. Chem Sci, 2013, 4: 3839

15 Zhou Z, Yan Y, Wang L, et al. Melanin-like nanoparticles decorated with an autophagy-inducing peptide for efficient targeted photothermal therapy. Biomaterials, 2019, 203: 63-72

16 Wang Y, Yang J, Liu H, et al. Osteotropic peptide-mediated bone targeting for photothermal treatment of bone tumors. Biomaterials, 2017, 114: 97-105

17 Evans BC, Hocking KM, Kilchrist KV, et al. Endosomolytic nanopolyplex platform technology for cytosolic peptide delivery to inhibit pathological vasoconstriction. ACS Nano, 2015, 9: 5893-5907

18 Wang X, Bao X, McFarland-Mancini M, et al. Investigation of the intracellular delivery of fluoresceinated peptides by a host-[2]rotaxane. J Am Chem Soc, 2007, 129: 7284-7293

19 Liu X, Wu F, Ji Y, et al. Recent advances in anti-cancer protein/ peptide delivery. Bioconjugate Chem, 2019, 30: 305-324

20 Shoji-Kawata S, Sumpter R, Leveno M, et al. Identification of a candidate therapeutic autophagy-inducing peptide. Nature, 2013, 494: 201-206

21 LaRochelle JR, Cobb GB, Steinauer A, et al. Fluorescence correlation spectroscopy reveals highly efficient cytosolic delivery of certain penta-arg proteins and stapled peptides. J Am Chem Soc, 2015, 137: 2536-2541

22 Schmidt S, Adjobo-Hermans MJW, Wallbrecher R, et al. Detecting cytosolic peptide delivery with the GFP complementation assay in the low micromolar range. Angew Chem Int Ed, 2015, 54: 1510515108

23 Rabideau AE, Pentelute BL. Delivery of non-native cargo into mammalian cells using anthrax lethal toxin. ACS Chem Biol, 2016, 11: 1490-1501

24 Zhang Z, Shen W, Ling J, et al. The fluorination effect of fluoroamphiphiles in cytosolic protein delivery. Nat Commun, 2018, 9: 1377

25 Xu Z, Ramishetti S, Tseng YC, et al. Multifunctional nanoparticles co-delivering Trp2 peptide and CpG adjuvant induce potent cytotoxic T-lymphocyte response against melanoma and its lung metastasis. J Control Release, 2013, 172: 259-265

26 Yan J, He W, Yan S, et al. Self-assembled peptide-lanthanide nanoclusters for safe tumor therapy: overcoming and utilizing biological barriers to peptide drug delivery. ACS Nano, 2018, 12: 2017-2026

27 Cheng Y. Fluorinated polymers in gene delivery. Acta Polym Sin, 2017, 8: 1234-1245
$28 \mathrm{Yu} \mathrm{X}, \mathrm{Gou} \mathrm{X}, \mathrm{Wu} \mathrm{P}$, et al. Activatable protein nanoparticles for targeted delivery of therapeutic peptides. Adv Mater, 2018, 30: 1705383

29 Chang H, Lv J, Gao X, et al. Rational design of a polymer with robust efficacy for intracellular protein and peptide delivery. Nano Lett, 2017, 17: 1678-1684

$30 \mathrm{Lv} \mathrm{J}, \mathrm{He} \mathrm{B}, \mathrm{Yu}$ J, et al. Fluoropolymers for intracellular and in vivo protein delivery. Biomaterials, 2018, 182: 167-175

31 Li G, Lei Q, Wang F, et al. Fluorinated polymer mediated transmucosal peptide delivery for intravesical instillation therapy of bladder cancer. Small, 2019, 15: 1900936

32 Lv J, Fan Q, Wang H, et al. Polymers for cytosolic protein delivery. Biomaterials, 2019, 218: 119358

33 Yu C, Tan E, Xu Y, et al. A guanidinium-rich polymer for efficient cytosolic delivery of native proteins. Bioconjugate Chem, 2019, 30: 413-417

34 Li G, Yuan S, Deng D, et al. Fluorinated polyethylenimine to enable transmucosal delivery of photosensitizer-conjugated catalase for photodynamic therapy of orthotopic bladder tumors postintravesical instillation. Adv Funct Mater, 2019, 29: 1901932

$35 \mathrm{Xu} \mathrm{J}$, Wang $\mathrm{H}, \mathrm{Xu} \mathrm{L}$, et al. Nanovaccine based on a proteindelivering dendrimer for effective antigen cross-presentation and cancer immunotherapy. Biomaterials, 2019, 207: 1-9

36 Yin L, Song Z, Kim KH, et al. Non-viral gene delivery via membrane-penetrating, mannose-targeting supramolecular selfassembled nanocomplexes. Adv Mater, 2013, 25: 3063-3070

37 Yang J, Zhang Q, Chang H, et al. Surface-engineered dendrimers in gene delivery. Chem Rev, 2015, 115: 5274-5300

38 Shen W, Wang Q, Shen Y, et al. Green tea catechin dramatically promotes RNAi mediated by low-molecular-weight polymers. ACS Cent Sci, 2018, 4: 1326-1333

39 Liu C, Wan T, Wang H, et al. A boronic acid-rich dendrimer with robust and unprecedented efficiency for cytosolic protein delivery and CRISPR-Cas9 gene editing. Sci Adv, 2019, 5: eaaw8922

40 Liu C, Shen W, Li B, et al. Natural polyphenols augment cytosolic protein delivery by a functional polymer. Chem Mater, 2019, 31: 1956-1965

41 Lv S, Wu Y, Cai K, et al. High drug loading and sub-quantitative loading efficiency of polymeric micelles driven by donor-receptor coordination interactions. J Am Chem Soc, 2018, 140: 1235-1238

42 Wang J, Zhang Z, Wang X, et al. Size- and pathotropism-driven targeting and washout-resistant effects of boronic acid-rich protein nanoparticles for liver cancer regression. J Control Release, 2013, 168: $1-9$

43 Wang J, Wu W, Zhang Y, et al. The combined effects of size and surface chemistry on the accumulation of boronic acid-rich protein nanoparticles in tumors. Biomaterials, 2014, 35: 866-878

44 Liu C, Shao N, Wang Y, et al. Clustering small dendrimers into nanoaggregates for efficient DNA and siRNA delivery with minimal toxicity. Adv Healthc Mater, 2016, 5: 584-592

45 Liu X, Xiang J, Zhu D, et al. Fusogenic reactive oxygen species triggered charge-reversal vector for effective gene delivery. Adv Mater, 2016, 28: 1743-1752

46 Piest M, Engbersen JFJ. Role of boronic acid moieties in poly (amido amine)s for gene delivery. J Control Release, 2011, 155: 331-340

47 Andersen KA, Smith TP, Lomax JE, et al. Boronic acid for the traceless delivery of proteins into cells. ACS Chem Biol, 2016, 11: 319-323

48 Kyte J, Doolittle RF. A simple method for displaying the hydro- 
pathic character of a protein. J Mol Biol, 1982, 157: 105-132

49 Fan B, Kang L, Chen L, et al. Systemic siRNA delivery with a dual $\mathrm{pH}$-responsive and tumor-targeted nanovector for inhibiting tumor growth and spontaneous metastasis in orthotopic murine model of breast carcinoma. Theranostics, 2017, 7: 357-376

50 Kim J, Lee YM, Kim H, et al. Phenylboronic acid-sugar grafted polymer architecture as a dual stimuli-responsive gene carrier for targeted anti-angiogenic tumor therapy. Biomaterials, 2016, 75: $102-111$

51 Ji M, Li P, Sheng N, et al. Sialic acid-targeted nanovectors with phenylboronic acid-grafted polyethylenimine robustly enhance siRNA-based cancer therapy. ACS Appl Mater Interfaces, 2016, 8: 9565-9576

52 Wang H, Huang Q, Chang H, et al. Stimuli-responsive dendrimers in drug delivery. Biomater Sci, 2016, 4: 375-390

53 Wang C, Sun Z, Liu Y, et al. A novel antimicrobial vermipeptide family from earthworm Eisenia fetida. Eur J Soil Biol, 2007, 43: S127-S134

54 Liu YQ, Sun ZJ, Wang C, et al. Purification of a novel antibacterial short peptide in earthworm Eisenia foetida. Acta Biochim Biophys Sin, 2004, 36: 297-302

55 Perea SE, Reyes O, Puchades Y, et al. Antitumor effect of a novel proapoptotic peptide that impairs the phosphorylation by the protein kinase 2 (casein kinase 2). Cancer Res, 2004, 64: 7127-7129

Acknowledgements This work was supported by the National Natural Science Foundation of China (21725402), the Science and Technology Commission of Shanghai Municipality (17XD1401600), and Guangdong Innovative and Entrepreneurial Research Team Program (2016ZT06C322). We thank the supports from the Flow Cytometry Core Facility and the Confocal Microscopy Facility at ECNU.

Author contributions Lv J synthesized and tested the peptide delivery efficacy of the polymer; Liu C performed part of peptide delivery experiments; Lv K contributed to the characterization of BDP/peptide complexes; Cheng $\mathrm{Y}$ and Wang $\mathrm{H}$ contributed to the theoretical analysis; Cheng Y and Lv J wrote the paper; all authors contributed to the general discussion.

Conflict of interest The authors declare that they have no conflict of interest.

Supplementary information online version of the paper.

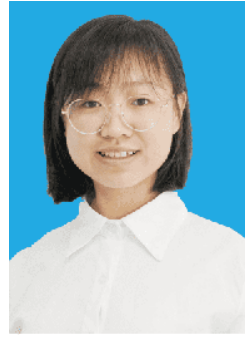

Jia Lv received her $\mathrm{PhD}$ degree from the East China Normal University in 2018. She is currently working as a postdoctoral fellow at South China University of Technology. Her research interests mainly focus on the intracellular delivery of biomacromolecules such as proteins and peptides.

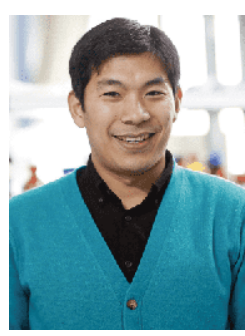

Yiyun Cheng is a full professor of biomedical engineering at the School of Life Sciences, East China Normal University. He received his $\mathrm{PhD}$ degree from the University of Science and Technology of China and was a postdoctoral fellow at Washington University in St. Louis, MO. His research interests focus on the rational design of polymers for the delivery of biomacromolecules such as DNA, RNA, proteins and peptides.

\section{苯硼酸修饰的树形高分子作为高效的多肽胞内递 送载体}

吕佳 ${ }^{1}$, 刘 崇懿 $^{2}$, 吕可歆 ${ }^{2}$, 王辉 ${ }^{1}$, 程义云 ${ }^{1,2^{*}}$

摘要 小肽及其类似物在生命活动中发挥着至关重要的作用. 开发 高效、安全的小肽胞内递送技术对于生物医药以及生命科学基础 研究都具有重要意义. 当前, 将不同性质的小肽高效递送到细胞中 并使其发挥生物学功能仍然面临挑战. 本文通过在树形高分子表 面修饰苯嗍酸基团得到一种小肽胞内递送载体. 该载体可以将不 同极性和带电性质的小肽高效、安全地递送到多种细胞系中. 与 传统的穿膜肽相比, 该方法对小肽的递送效率更高, 同时能够更加 有效地保护小肽避免其被蛋白酶降解, 维持其生物学活性. 通过该 研究, 我们得到了一种高效、通用的小肽胞内递送方法, 为小肽递 送载体的理性设计提供了新的思路. 